\title{
TINGKAT KEBERHASILAN MODEL RESTORASI DI PONDOK INJUK KAWASAN TAMAN NASIONAL GUNUNG HALIMUN-SALAK : Studi Kasus Kampung Cimapag, Sebagai Model Kampung Konservasi (Study of Restoration Model in Pondok Injuk Area of National Park Gunung Halimun Salak : A Case study of Kampong Cimapag as a Model of Kampong Conservation)*)
}

\author{
Oleh/By: \\ Aditya Hani dan/and Encep Rachman \\ Balai Penelitian Kehutanan Ciamis \\ Jl. Raya Ciamis-Banjar Km. 4 PO. BOX. 5 Ciamis 46201 Telp. (0265) 771352, Fax (0265) 775866
}

*) Diterima : 04 Januari 2007; Disetujui : 18 Desember 2007

\begin{abstract}
This research executed at Kampong Cimapaga, Sirnaresmi Village, Sukabumi District West Java. Target of this research was to study an application of conducted restoration model at Kampong Cimapag area of Pondok Injuk. Area of Pondok Injuk National Park Gunung Halimun Salak (TNGHS) presented experiences of resident pressures coming from community who live in and around the area, and who depended on forest product and land of area. These condition were distinguished by the existence of illegal logging activity and land use for farming. Restoration represented one of actions to return community involvement and to make ecosystem to function initialy in the national park area. Society Kampong Conservation (MKK) Cimapag in the year 2004 was established to prevent illegal logging and farm at the area of TNGHS. Activities of the restoration were conducted by six society groups covering activity of collecting crop seeds, planting and maintenance. Up to now, the wide of planted area was $49.5 \mathrm{ha}$, on which 19,817 plants consisted of rasamala, puspa, and huru were planted. Applied restoration model at kampong of Cimapag had not yet fulfill requirement of local society on forest product and wood, agriculture product, firewood and food for livestock. However it could lessen farm activities and illegal logging in the area of TNGHS. It is suggested to make zonation in the national park area in order to be more focused on its management which is conducted by a collaborative approach. Besides that, to fulfill requirement of society on firewood, livestock feed and agriculture product at Society Kampong Conservation Cimapag, on agroforestry system can be applied.
\end{abstract}

Key words : National park, restoration, society kampong conservation, land use

\begin{abstract}
ABSTRAK
Penelitian ini dilaksanakan di Kampung Cimapag, Desa Sirnaresmi, Kabupaten Sukabumi, Jawa Barat. Tujuan penelitian ini adalah untuk mengkaji keberhasilan penerapan model restorasi yang dilaksanakan oleh masyarakat Kampung Cimapag sehingga diharapkan menjadi model yang dapat diterapkan bagi pengelola Taman Nasional lainnya. Penelitian ini dilakukan dengan pengumpulan data primer dan data sekunder. Data primer dilakukan dengan cara wawancara dengan metode purposive sampling terhadap anggota kelompok Masyarakat Kampung Konservasi (MKK) yang berjumlah 15 responden. Data sekunder diperoleh dari hasil laporan penelitian yang telah dilakukan sebelumya. Hasil penelitian menunjukkan bahwa kawasan Pondok Injuk Taman Nasional Gunung Halimun Salak (TNGHS) merupakan salah satu tempat yang mengalami kerusakan akibat adanya tekanan penduduk berupa penebangan pohon dan pembukaan hutan untuk lahan pertanian. Untuk mengembalikan kepada kondisi seperti semula, Balai TNGHS mengupayakan melalui kegiatan restorasi dengan pendekatan pemberdayaan masyarakat. Kegiatan yang dikembangkan yaitu pembentukan MKK yang telah dimulai sejak tahun 2004. Model Kampung Konservasi mempunyai tiga kegiatan pokok meliputi : 1) Memperbaiki atau merehabilitasi kawasan TNGHS yang rusak, 2) Observasi kawasan TNGHS secara bersama-sama dengan masyarakat lokal dengan tujuan untuk memantau situasi sekaligus untuk mengurangi kegiatan-kegiatan illegal, serta menjalin hubungan yang baik antara TNGHS dengan masyarakat lokal melalui komunikasi yang intens, dan 3) Untuk meningkatkan kegiatan ekonomi masyarakat. Kegiatan restorasi yang telah dilaksanakan oleh masyarakat Kampung Cimapag antara lain melakukan penanaman secara swadaya tanaman kayu-kayuan jenis asli setempat. Luas lahan yang berhasil ditanami adalah 49,5 ha dengan 19.817 bibit pohon terdiri dari rasamala (Altingia excelsa Noronha), puspa (Schima wallichii Reinw), dan huru (Litsea javanica BL). Bibit pohon yang ditanam berasal dari cabutan anakan alam yang ada di sekitar Kampung Cimapag.
\end{abstract}

Kata kunci : Model kampung konservasi, penggunaan lahan, restorasi, taman nasional 


\section{PENDAHULUAN}

Taman Nasional Gunung HalimunSalak (TNGHS) dengan luas 113.357 ha merupakan kawasan hutan hujan pegunungan yang terletak di Provinsi Jawa Barat (Kabupaten Sukabumi dan Bogor) dan Provinsi Banten (Kabupaten Lebak). Ekosistem hutan alam ini berfungsi sebagai pengatur tata air, iklim mikro, pengawetan flora dan fauna, sebagai tempat pendidikan, penelitian, latihan serta penunjang budidaya dan pariwisata alam (Departemen Kehutanan, 2007). Sebagian kawasan TNGHS telah mengalami deforestasi, seperti yang terjadi di kawasan Pondok Injuk yang berbatasan langsung dengan Kampung Cimapag, Desa Sirnaresmi, Kecamatan Cisolok, Kabupaten Sukabumi. Kerusakan terjadi akibat aktivitas penebangan liar dan penggunaan lahan/perambahan untuk lahan pertanian masyarakat.

Kebutuhan lahan dan hasil hutan akan terus meningkat seiring dengan penambahan jumlah penduduk yang ada di sekitar kawasan Pondok Injuk. Akibatnya, daya dukung kawasan semakin berkurang, serta akan mengancam kelestarian flora dan fauna yang ada. Sriyanto et al. (2005) dalam Setio dan Mukhtar (2005) menyampaikan salah satu bentuk tindakan yang dapat diterapkan yaitu yang disebut restorasi, di mana kegiatannya ditekankan pada pemulihan ekosistem melalui revegetasi secara aktif dengan spesies yang semula ada, sehingga mencapai struktur dan komposisi spesies seperti semula. Restorasi di kawasan konservasi perlu mempertimbangkan aspek ekologis dan pengaturan akses kepada masyarakat. Oleh karena itu perlu sebuah model restorasi yang memungkinkan aksesnya diterima oleh masyarakat melalui penanaman jenis asli sekaligus bermanfaat bagi masyarakat di mana tanaman obat/palawija sebagai tanaman selanya. Pemberian akses kepada masyarakat, dapat memberikan alternatif pendapatan untuk jangka pendek dari tanaman tumpangsari dan jangka panjang dari hasil hutan non kayu dan tanaman penghidupan. Akhirnya kegiatan restorasi dapat memberikan manfaat ganda yaitu perbaikan ekosistem dan peningkatan kesejahteraan masyarakat (Departemen Kehutanan, 2007).

Model Kampung Konservasi (MKK) merupakan salah satu model yang dikembangkan pihak Balai TNGHS dalam upaya merestorasi kawasan hutannya yang telah rusak serta bentuk pendekatan kepada masyarakat untuk membangun kesadaran akan pentingnya kelestarian hutan. MKK dilaksanakan sejak tahun 2004 dan selama satu tahun keberadaannya telah melaksanakan beberapa kegiatan terutama dalam upaya merestorasi kawasan hutan. Oleh karena itu penelitian ini bertujuan untuk memperoleh informasi tentang keberhasilan kegiatan restorasi yang dilaksanakan oleh masyarakat sehingga informasi ini diharapkan dapat menjadi masukan bagi pihak pengelola TNGHS maupun balai taman nasional lainnya.

\section{METODE PENELITIAN}

\section{A. Waktu dan Lokasi}

Penelitian dilaksanakan selama dua bulan, dari bulan Desember 2005 sampai dengan Januari 2006. Lokasi penelitian dilaksanakan di Blok Pondok Injuk, Kampung Cimapag, Desa Sinaresmi, Kecamatan Cisolok. Lokasi ini termasuk dalam wilayah kerja Resort Gunung Bodas, Seksi Konservasi Wilayah III Sukabumi, TNGHS.

\section{B. Bahan dan Alat}

Bahan dan peralatan yang digunakan dalam penelitian ini antara lain tanaman restorasi yang dijadikan sampel kajian, kuesioner, tape recorder (walkman), roll meter, kamera, dan alat tulis.

\section{Metode}

\section{Teknik Pengambilan Data}

Data yang dikumpulkan terdiri dari data primer dan data sekunder. 


\section{a. Data Primer}

Data primer dikumpulkan dengan cara observasi lapangan tempat dilaksanakannya restorasi oleh masyarakat setempat.

\section{b. Data Sekunder}

Pengumpulan data sekunder yaitu dari berbagai laporan hasil penelitian, baik perorangan maupun lembaga. Data sekunder meliputi keadaan biofisik (topografi, tanah, iklim, letak dan luas kawasan, hidrologi, pertumbuhan tanaman restorasi), keadaan sosial ekonomi (di antaranya jumlah penduduk, mata pencaharian, dan pendidikan), serta data tanaman hasil penanaman oleh masyarakat, termasuk data laporan kelompok MKK.

Wawancara dilakukan dengan tanya jawab secara langsung dengan masyarakat, jumlah responden sebanyak 15 responden yang merupakan keseluruhan anggota kelompok MKK. Pengambilan sampel dilaksanakan dengan metode purposive sampling atau pengambilan sampel dengan cara disengaja, yaitu anggota kelompok MKK.

\section{Metode Analisis Data}

Data yang terkumpul diolah dan dianalisis dengan menggunakan statistik deskriptif yang kemudian disajikan secara kualitatif dan kuantitatif.

\section{KEADAAN UMUM TAMAN NA- SIONAL GUNUNG HALIMUN- SALAK DAN MODEL KAM- PUNG KONSERVASI}

\section{A. Letak dan Luas}

Secara geografis TNGHS terletak di antara 106”21' BT dan 106”38' BT, dan di antara 6"31' dan 6"37' LS, di bagian barat daya Provinsi Jawa Barat. Berdasarkan administrasi pemerintahan, TNGHS terletak di dalam tiga Kabupaten yaitu Bogor, Sukabumi, dan Lebak. Luas keseluruhan TNGHS adalah 113.357 hektar (Departemen Kehutanan, 2007).

\section{B. Bentang Alam}

Secara umum TNGHS memiliki bentang alam bervariasi dari dataran ke pegunungan, yang sebagian besar berbukit dan bergunung. Ketinggiannya juga bervariasi dari $500 \mathrm{~m}$ dpl sampai dengan $2.211 \mathrm{~m}$ dpl (Gunung Salak). Sebagian besar kawasan $(75,7 \%)$ terletak pada ketinggian di bawah $1.400 \mathrm{~m}$ dpl dengan kelerengan di atas 45\% (Departemen Kehutanan, 2007).

\section{Tanah}

Terdapat 12 tipe tanah di kawasan TNGHS yang digolongkan menjadi dua kelompok, yaitu andosol dan latosol, pada umumnya tanahnya subur karena secara geologis, kawasan Gunung Halimun terbentuk oleh pegunungan tua yang terbentuk akibat adanya gerakan tektonik yang mendorong ke atas. Untuk kawasan pada bagian Gunung Salak merupakan gunung berapi strato type $\mathrm{A}$, di mana tercatat terakhir Gunung Salak meletus tahun 1938, memiliki kawah yang masih aktif dan lebih dikenal dengan nama Kawah Ratu (Departemen Kehutanan, 2007).

\section{Iklim}

Menurut klasifikasi iklim Schmidt dan Ferguson, TNGH termasuk ke dalam golongan iklim A dengan curah hujan rata-rata 4.000-6.000 mm/tahun, musim hujan terjadi pada bulan Oktober-April, musim kemarau berlangsung bulan Mei-September (Departemen Kehutanan, 2007).

\section{E. Hidrologi}

Pegunungan Halimun merupakan daerah tangkapan air yang penting, dan merupakan sumber dari beberapa sungai yang mengalir di daerah pertanian dan perkotaan di Jawa Barat, baik ke arah selatan maupun utara. Terdapat lebih dari 50 sungai dan anak sungai mengalir dari TNGHS ke Laut Jawa maupun ke Samudera Hindia. Terdapat 11 anak sungai utama yang mengalir dari TNGHS yang selalu berair meskipun pada musim kering. 
Sungai-sungai tersebut antara lain Ciberang-Ciujung, Cidurian, Cisadane, Cimadur, Citarik, dan Citatih (Departemen Kehutanan, 2007).

\section{F. Keadaan Umum Kampung Cima- pag}

Cimapag merupakan salah satu kampung yang masuk di Desa Sirnaresmi, terletak pada ketinggian antara 600-1.230 m dpl. Kampung ini termasuk daerah di luar kawasan taman nasional namun berbatasan langsung dengan kawasan taman nasional. Penduduk Kampung Cimapag berjumlah 737 jiwa dalam 182 KK (kepala keluarga). Masyarakat Kampung Cimapag masih memiliki pemimpin non formal yang disebut kepala adat, di mana aturan dan tradisi adat setempat masih berlaku dan ditaati oleh masayarakat setempat. Mata pencaharian penduduk hampir sebagian besar sebagai petani, baik menggarap di lahan milik sendiri maupun di lahan negara yaitu di kawasan hutan taman nasional. Luas kepemilikan lahan masyarakat sangat rendah (kurang dari 0,25 ha) sehingga belum dapat mencukupi kebutuhan hidup sehari-hari, sementara alternatif pekerjaan bagi mereka sangat terbatas yaitu sebagai pengrajin gula aren, berdagang maupun beternak yang umumnya hanya memiliki beberapa individu unggas atau kambing. Di lain pihak, tingkat pendidikan dan keterampilan masyarakat pada umumnya rendah, hanya berpendidikan sekolah dasar, sehingga tingkat ketergantungan masyarakat terhadap hutan dan lahan hutan masih sangat tinggi (Balai Taman Nasional Gunung Halimun Salak dan JICA, 2004). Gambaran umum pola pemanfaatan lahan di Kampung Cimapag, Desa Sirnaresmi dapat dilihat pada sketsa Gambar 1.

Gambar 1 dapat dijelaskan sebagai berikut :

1. Hutan pinus (pine forest), kawasan ini merupakan kawasan eks Perum Perhutani yang kondisinya sudah rusak karena ditebangi oleh penebang liar. Banyak lahan yang gundul dimanfaatkan masyarakat untuk menanam padi huma dan tanaman palawija.

2. Kebun talun (private mixed forest), merupakan kawasan milik pribadi yang dikelola dengan baik dan ditanami dengan tanaman buah-buahan dan kayu.

3. Sungai (river), air sungai bersumber dari hutan TNGHS yang airnya digunakan untuk keperluan pengairan sawah dan rumah tangga.

4. Sawah (rice field), kawasan tanah berair yang digunakan untuk menanam padi lokal.

5. Pemukiman (residence), pola pemukiman masyarakat mengumpul dengan jarak yang sangat berdekatan sehingga hampir sebagian besar tidak memiliki pekarangan.

6. Jalan desa (country road) yang ada masih merupakan jalan batu yang kondisinya sudah rusak, hanya dapat dilalui oleh motor ataupun mobil yang mempunyai dua penggerak (handle).

7. Kebun (field), kawasan ini dikelola secara pribadi dan ditanami dengan tanaman kopi (Koffie), pisang (Mimosa pudica), kayu, cengkeh (Miristica spp.), dan palawija.

\section{HASIL DAN PEMBAHASAN}

\section{A. Interaksi Masyarakat dengan Ka- wasan Hutan}

Kerusakan yang terjadi pada kawasan taman nasional disebabkan karena masih tingginya tingkat ketergantungan masyarakat terhadap hutan, karena kebutuhan kayu bakar, bahan bangunan, pakan ternak, dan lahan untuk pertanian masyarakat. Tingginya tingkat ketergantungan masyarakat Kampung Cimapag dengan kawasan hutan taman nasional disajikan pada Tabel 1 dan Tabel 2. Jenis dan penggunaannya oleh masyarakat yang diperoleh dari kawasan hutan tersebut disajikan pada Tabel 3.

Dari hasil wawancara dengan masyarakat Kampung Cimapag, Desa Sirnaresmi seperti yang disajikan pada Tabel 1, 


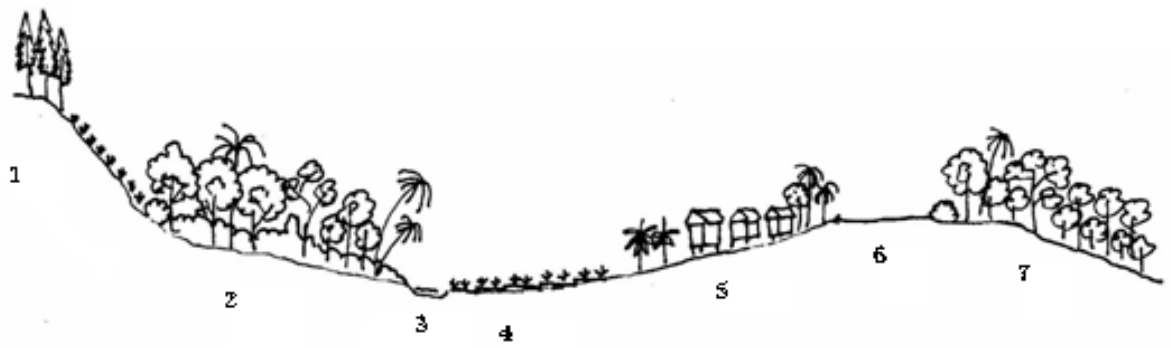

Gambar (Figure) 1. Sketsa pola pemanfaatan lahan di Kampung Cimapag, Desa Sirnaresmi, Sukabumi Sumber (Source) : BTNGHS-JICA (2004) (Landuse pattern at Kampong Cimapag, SirnaresmiVillage, Sukabumi)

Tabel (Table) 1. Tingkat interaksi masyarakat Kampung Cimapag, Desa Sirnaresmi, Kabupaten Sukabumi ke dalam kawasan TNGHS (Degree of interaction of Kampong Cimapag, Sinaresmi Village, Sukabumi District, peoples into TNGHS area) Intensitas (Intencity) Jumlah responden (Respondent) $\quad$ Persen (Percent) (\%)

a. Jarang/Rarely (1-5 hari/bulan) 20

b. Kadang-kadang/Occasionally (8-12 hari/bulan) 46,7

c. Sering/Often (20-26 hari/bulan) 33,3

Total $15 \quad 100$

Catatan (Notes): Masyarakat tidak melakukan aktivitas di hutan pada hari Jum'at (Unactivities society at Friday in the forest)

Tabel (Table) 2. Aktivitas masyarakat Kampung Cimapag, Desa Sirnaresmi, Kabupaten Sukabumi di dalam kawasan TNGHS (People activities at Kampong Cimapag, Sirnaresmi Village, Sukabumi District in TNGHS area)

\begin{tabular}{lllc}
\hline No & \multicolumn{1}{c}{ Kegiatan (Activties) } & \multicolumn{1}{c}{ Intensitas (Intencity) } & $\begin{array}{c}\text { Jumlah responden } \\
\text { (Responden) }\end{array}$ \\
\hline 1 & $\begin{array}{l}\text { Mengambil kayu bakar } \\
\text { (To take fuelwood) }\end{array}$ & $\begin{array}{l}\text { a. Tidak pernah (0 hari) } \\
\text { b. Kadang-kadang (8-12 hari/bulan) }\end{array}$ & 0 \\
& & c. Sering (20-26 hari/bulan) & 13 \\
\hline 2 & Mengambil kayu untuk keperluan lain & a. Tidak pernah (0 hari) & 10 \\
& (To take timber wood to other necessary) $)$ & b. Kadang-kadang (8-12 hari/bulan) & 4 \\
& c. Sering (20-26 hari/bulan) & 1 \\
\hline 3 & Mengolah lahan/kebun & a. Tidak pernah (0 hari) & 0 \\
& (To prepare land/garden) & b. Kadang-kadang (8-12 hari/bulan) & 1 \\
& c. Sering (20-26 hari/bulan) & 14 \\
\hline 4 & Mengambil pakan ternak & a. Tidak pernah (0 hari) & 7 \\
(To take animal feed) & b.Kadang-kadang (8-12 hari/bulan) & 2 \\
& c. Sering (20-26 hari/bulan) & 6 \\
\hline
\end{tabular}

Tabel (Table) 3. Jenis tanaman beserta penggunaannya oleh masyarakat Kampung Cimapag, Desa Sirnaresmi, Kabupaten Sukabumi (Plant species and utilities by peoples at Kampong Cimapag, Sinaresmi Village, Sukabumi District)

\begin{tabular}{|c|c|c|}
\hline No & $\begin{array}{l}\text { Tujuan penggunaan } \\
\text { (Purpose of planting) }\end{array}$ & Jenis tanaman (Plant species) \\
\hline 1 & Kayu bakar (Fuelwood) & $\begin{array}{l}\text { Jeunjing (Paraserianthes falcataria), bambu (Dendrocalamus sp.), } \\
\text { kaliandra (Callandra sp.), tisuk (Hibiscus macropylus) }\end{array}$ \\
\hline 2 & $\begin{array}{l}\text { Bahan bangunan (Timber } \\
\text { wood) }\end{array}$ & $\begin{array}{l}\text { Huru (Litsea javanica BL), puspa (Schima wallichii), jeunjing (Pa- } \\
\text { raserianthes falcataria), tisuk (Hibiscus macropylus), manglid } \\
\text { (Manglieta glauca), afrika (Maesopsis manii), bambu (Dendrocala- } \\
\text { mus sp.), dan kirey (Metroxylon spec.). }\end{array}$ \\
\hline 3 & Obat-obatan (Medicine) & $\begin{array}{l}\text { Kapolaga (Amomum cardamomum), jahe (Zingiber officinale), ku- } \\
\text { nyit (Curcuma domestica VAL), kencur (Kaempferia galaga LINN) }\end{array}$ \\
\hline 4 & Pakan ternak (Animal feed) & $\begin{array}{l}\text { Nangka (Arthocapus integra), hamerang (Ficus toxicaria LINN), } \\
\text { jampang (Eleusine indica GAERTN) }\end{array}$ \\
\hline
\end{tabular}


Tabel 2, dan Tabel 3, pada umumnya mempunyai tingkat interaksi yang tinggi terhadap hutan. Aktivitas tertinggi masyarakat adalah mengolah lahan dan mencari kayu bakar. Dalam satu minggu ratarata satu rumah tangga menggunakan dua ikat kayu bakar. Masyarakat mencari kayu bakar, yang diambil dari kawasan hutan minimal dua kali dalam seminggu. Dengan asumsi 20 ikat sama dengan satu $\mathrm{m}^{3}$, maka untuk $182 \mathrm{KK}$ dalam satu minggu mengambil kayu bakar sebanyak 18,2 $\mathrm{m}^{3}$ kayu bakar. Pohon yang digunakan untuk kayu bakar biasanya dari pohon-pohon yang sudah tumbang ataupun dari sisa-sisa penebangan liar yang masih banyak ditemukan. Aktivitas mencari kayu bakar selalu dilakukan bersamaan dengan aktivitas berkebun. Kebutuhan kayu bakar cenderung meningkat, dan sudah tidak ada lagi pohon yang tumbang atau sisa penebangan liar maka dapat menjadi ancaman serius bagi keberadaan pohonpohon di dalam hutan, apabila tidak ada upaya dari masyarakat menanam pohon untuk kayu dalam memenuhi kebutuhannya. Salah satu contoh pengambilan kayu bakar di desa ini dapat dilihat pada Gambar 2.

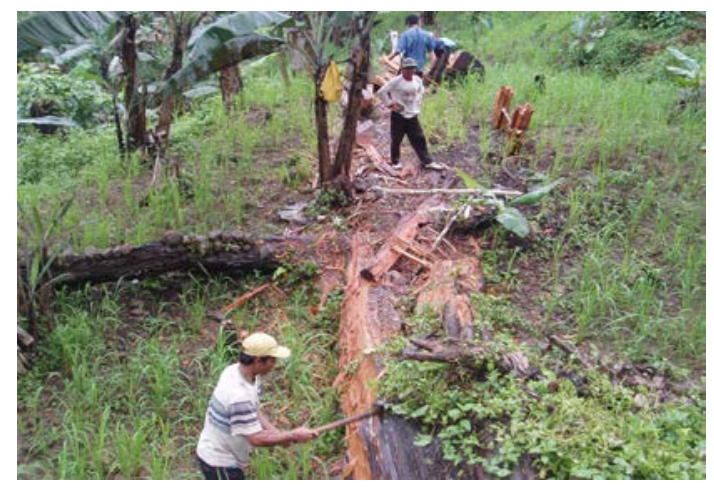

Gambar (Figure) 2. Aktivitas masyarakat Desa Sirnaresmi dalam mencari kayu bakar (Peoples of Sirnaresmi Village on taking fuelwood activities)

Aktivitas mencari pakan ternak juga menjadi keseharian bagi sebagian penduduk. Tumbuhan bawah hutan yang biasa dimanfaatkan antara lain hamerang, jampang, capung, dan garehong. Aktivitas ini biasa dilakukan bersamaan dengan ketika mereka pergi ke lahan garapan secara bergantian dengan aktivitas mencari kayu bakar. Cara beternak masyarakat sebagian dengan sistem kandang tetapi sebagian lagi masih menggunakan pola penggembalaan liar, sehingga seringkali ada ternak yang merusak tanaman petani.

Lahan pertanian masyarakat berupa lahan milik dan lahan negara yaitu di kawasan TNGHS. Masyarakat masuk kawasan TNGHS karena lahan miliknya sangat sempit. Sebelumnya, lahan pertanian yang ada di dalam kawasan merupakan hutan pinus yang dikelola oleh Perum Perhutani yang keadaannya sudah gundul akibat adanya kegiatan penebangan secar besar-besaran terutama pada tahun 2002. Jenis-jenis tanaman yang diusahakan oleh petani pada lahan pertanian disajikan pada Tabel 4.

Masyarakat yang bertani di kawasan TNGHS dengan menanam tanaman semusim seperti padi (Oryza sativa LINN), cabai (Capsium frutescens LINN), kucai (Allium odorum LINN), trubuk (Sacharum officinarum LINN), jagung (Zea ma$y$ s), mentimun (Cucumus sativus LINN) serta pisang (Mimosa pudica). Pada umumnya hasil pertanian untuk konsumsi sendiri kecuali pisang yang banyak dijual ke luar daerah. Kepemilikan lahan masyarakat sangat sempit (rata-rata $<0,5$ ha), yang terletak di bagian atas pemukiman dengan kondisi topografi berbukit dan kemiringan lereng mencapai $45^{\circ}$. Kondisi ini menimbulkan terjadinya erosi permukaan setiap musim hujan. Ketergantungan yang sangat tinggi terhadap kawasan hutan (TNGHS) mengakibatkan masyarakat tidak lagi peduli terhadap larangan untuk tidak melakukan aktivitas bertani di kawasan pelestarian alam. Oleh karena itu untuk merubah kebiasaan masyarakat agar tidak bertani di kawasan TNGHS dilakukan secara bertahap dengan melakukan berbagai macam pendekatan yang lebih mengarah membangun kesadaran masyarakat tentang pentingnya menjaga kelestarian taman nasional. Selain itu, untuk mengurangi ketergantungan masyarakat terhadap hutan melalui pembentukan kegiatan ekonomi alternatif antara lain berdagang dan membuat kerajinan. 
Tabel (Table) 4. Jenis tanaman yang ditanam di ladang garapan petani Kampung Cimapag, Desa Sirnaresmi, Kabupaten Sukabumi (Plant species were planted on farmer lands at Kampong Cimapag, Sirnaresmi Village, Sukabumi District)

\begin{tabular}{ll}
\multicolumn{1}{c}{$\begin{array}{c}\text { Pengelompokan tanaman } \\
\text { (Plants group) }\end{array}$} & \multicolumn{1}{c}{$\begin{array}{c}\text { Jenis tanaman } \\
\text { (Plant species) }\end{array}$} \\
\hline $\begin{array}{l}\text { Tanaman kayu-kayuan } \\
\text { (Woody plant) }\end{array}$ & $\begin{array}{l}\text { Puspa (Schima wallichii), rasamala (Altingia excelsa), huru (Litsea javani- } \\
\text { ca), cempaka, kianak, pasang (Quercus paranica), jeunjing (Paraseri- } \\
\text { anthes falcataria), manii (Maesopsis manii), tisuk (Hybiscus macropylus), } \\
\text { manglid (Manglieta glauca), bambu (Dendrocalamus sp.) }\end{array}$ \\
$\begin{array}{l}\text { Tanaman semusim } \\
\text { (Seasonaly plant) }\end{array}$ & $\begin{array}{l}\text { Pisang (Mimosa pudica), cabe rawit (Capsium frutescens LINN), terubuk } \\
\text { (Sacharum officinarum LINN), kucai (Allium odorum LINN), padi (Oryza }\end{array}$ \\
& sativa LINN), jagung (Zea mays), kacang merah (Phateohs vulgaris), na- \\
& nas (Ananas comusus), ubi (Ipomea batatas POIR), sawi (Brassica rugosa \\
Tanaman tahunan & PRAIN) \\
(Anualy plant) & pus integra), rambutan (Nephelium spp.), mangga (Mangifera indica), \\
& petai (Parkia speciosa), jengkol (Phitelobium lobatum), cengkeh (Miris- \\
tica sp.), kopi (Koffie), kelapa (Cocus nucifera), melinjo (Gnetum gne- & \\
mon) & Kapolaga (Amomum cardamomum), jahe (Zingiber officinale) \\
Tanaman empon-empon & \\
(Medicine plant) &
\end{tabular}

\section{B. Restorasi Hutan Dengan Pendekat- an Model Kampung Konservasi}

Usaha memperbaiki kondisi hutan melalui kegiatan restorasi mempunyai tantangan yang cukup berat. Pendekatan yang dilakukan oleh pihak TNGHS yaitu dengan cara pelibatan masyarakat dalam kegiatan restorasi, baik untuk penanaman, pemeliharaan maupun penjagaan keberadaan tanaman hasil restorasi. Dalam melaksanakan kegiatan restorasi hutan masyarakat tergabung dalam kelompok Masyarakat Kampung Konservasi (MKK), yang dikelompokkan menjadi enam kelompok. Tujuan dari pengelompokan ini untuk memudahkan dalam pengorganisasian, pengaturan, dan pengawasan. Dengan adanya kelompok tersebut diharapkan semua kegiatan dalam MKK dapat dilaksanakan secara bersama-sama. Bentuk pengorganisasian masyarakat yaitu adanya susunan kepengurusan, sistem pembagian lahan garapan dan lahan yang akan ditanami untuk masing-masing kegiatan. Untuk menjaga agar tidak terjadi penyalahgunaan hak pengelolaan lahan, maka dibuat aturan bersama dalam bentuk memorandum of understanding (MOU). Dalam aturan ini dimuat berbagai hak dan kewajiban bagi pihak pengelola taman nasional maupun masyarakat serta larangan serta sanksi yang harus diperhatikan oleh masyarakat. Sebagai gambaran terjadinya Masyarakat Kampung Konservasi di Kampung Cimapag, Desa Sirnaresmi dapat dilihat pada Tabel 5.

Terbentuknya MKK didasari pada kondisi hutan yang berbatasan langsung dengan perkampungan penduduk yang mengalami kerusakan akibat adanya aktivitas masyarakat di dalam hutan, serta masih tingginya ketergantungan masyarakat terhadap hutan dalam memenuhi kebutuhan hidupnya. MKK lebih diarahkan pada bentuk pemberdayaan masyarakat serta dalam jangka panjangnya mengurangi ketergantungan masyarakat terhadap hutan. Hasil penelitian di lapangan terhadap tiga kegiatan pokok MKK diuraikan sebagai berikut :

\section{Kegiatan Restorasi Hutan oleh Ma- syarakat}

Kegiatan ini dilakukan secara partisipatif dalam bentuk pengadaan bibit, penanaman, dan pemeliharaan. Hasil kegiatan penanaman dalam rangka kegiatan restorasi yang dilakukan oleh masyarakat Kampung Cimapag disajikan pada Tabel 6. 
Tabel (Table) 5. Proses terbentukya Model Kampung Konservasi (MKK) Kampung Cimapag, Desa Sirnaresmi, Kabupaten Sukabumi (Formed process of kampong conservation model at Kampong Cimapag, Sirnaresmi Village, Sukabumi District)

\begin{tabular}{|c|c|}
\hline Tahun (Year) & Kejadian (Activities \\
\hline 1979 & Perum Perhutani menanam rasamala di kawasan Pondok Injuk \\
\hline $1999-2000$ & Pelebaran jalan untuk akses ekonomi masyarakat \\
\hline \multirow[t]{2}{*}{2000} & a. Penebangan liar mulai terjadi \\
\hline & b. Pelebaran jalan memudahkan orang melakukan penebangan \\
\hline 2001 & Bekas penebangan liar ditanami padi dan pisang (musim tanam pertama) \\
\hline 2002 & Huma bertambah luas \\
\hline 2003 & $\begin{array}{l}\text { a. Perluasan taman nasional } \\
\text { b. Musim tanam kedua padi dan pisang }\end{array}$ \\
\hline 2004 & $\begin{array}{l}\text { a. Pemerintah Daerah Sukabumi bersama Balai TNGHS, lembaga swadaya masyarakat } \\
\text { (LSM) dan Japan International Corporation Agency (JICA) mengadakan studi sosial } \\
\text { ekonomi di desa penyangga kawasan TNGHS }\end{array}$ \\
\hline & b. Pembentukan MKK yang terdiri dari enam kelompok \\
\hline & c. Dengan adanya MKK perladangan liar dilokalisasi \\
\hline 2005 & $\begin{array}{l}\text { a. Kegiatan perladangan terbatas pada luasan MKK } 10 \text { ha, sementara masyarakat sudah } \\
\text { menggarap } 25 \text { ha, sehingga terjadi penambahan luasan MKK menjadi } 25 \text { ha } \\
\text { b. MKK masih memerlukan pembinaan dan pengawasan }\end{array}$ \\
\hline
\end{tabular}

Sumber (Source): TNGHS-JICA (2004)

Tabel (Table) 6. Hasil kegiatan penamanan restorasi hutan oleh masyarakat Kampung Cimapag, Desa Sirnaresmi, Kabupaten Sukabumi (Planting products of restoration activities by peoples of Kampong Cimapag, Sirnaresmi Village, Sukabumi District)

\begin{tabular}{lccccccc}
\hline \multirow{2}{*}{ Jenis tanaman (Plant species) } & \multicolumn{7}{c}{ Jumlah (Amount) } \\
\cline { 2 - 8 } & Kel. 1 & Kel. 2 & Kel. 3 & Kel. 4 & Kel. 5 & Kel. 6 & Total (Pohon/Tree) \\
\hline Rasamala & 1.300 & 1.115 & 695 & 1.270 & 554 & 315 & 5.249 \\
Puspa & 2.895 & 1.601 & 2.205 & 1.207 & 1.326 & 790 & 10.024 \\
Huru & 770 & 1.091 & 515 & 477 & 216 & 185 & 3.254 \\
\hline Total & 4.965 & 3.807 & 3.415 & 2.954 & 2.096 & 1.290 & 18.527 \\
\hline
\end{tabular}

Keterangan (Remark): Kel. = Kelompok (Group)

Penanaman dilakukan dengan jarak tanam $5 \mathrm{~m}$ x $5 \mathrm{~m}$. Jumlah tanaman yang berhasil ditanam oleh masyarakat sebanyak 18.527 pohon. Total luas lahan yang ditanami oleh masyarakat $\pm 46,32$ ha. Bibit tanaman yang digunakan oleh masyarakat berasal dari cabutan anakan alam dari kawasan hutan yang masih baik ataupun dari lahan milik masyarakat sendiri. Kegiatan restorasi dengan melibatkan masyarakat diperoleh empat keuntungan yaitu : (a) Biaya penanaman menjadi murah, (b) Pemeliharaan dilakukan oleh masyarakat sehingga tanaman diharapkan dapat tumbuh baik, (c) Dalam waktu cepat dapat menanami lahan yang luas, dan (d) Masyarakat lebih merasa memiliki pohon yang mereka tanam sendiri sehingga berusaha untuk menjaganya. Bibit yang digunakan oleh masyarakat untuk digunakan dalam kegiatan restorasi ditampilkan pada Gambar 3.

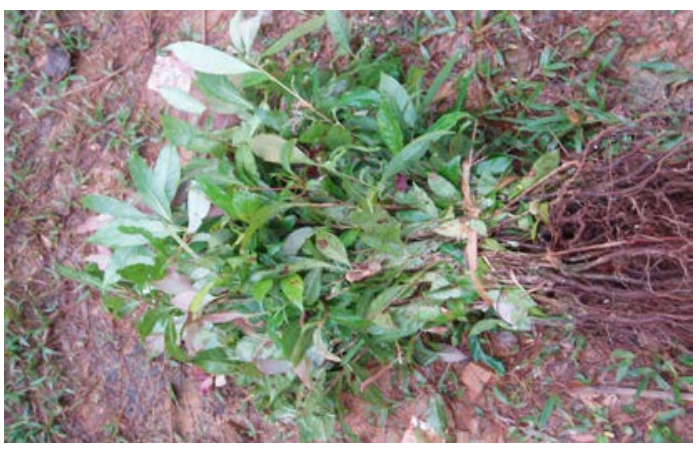

Gambar (Figure) 3. Bibit tanaman untuk kegiatan restorasi di Kampung Cimapag, Desa Sirnaresmi (Sample of plant seed forestoration at Kampong Cimapag, Sirnaresmi Village)

Dibandingkan dengan standar biaya pembuatan tanaman reboisasi pada kawasan konservasi pada tahun 2005 yang 
menetapkan biaya penanaman Rp 1.977.000,-/ha, maka kegiatan penanaman yang dilakukan oleh masyarakat telah menghemat anggaran sebesar Rp 91.574.640,- untuk luasan 46,32 ha. Kegagalan penanaman reboisasi seringkali terjadi karena kegiatan penanaman tidak diikuti dengan pemeliharaan, padahal dengan adanya keterlibatan masyarakat maka pemeliharaan telah dilaksanakan oleh masyarakat bersamaan dengan pemeliharaan tanaman pertaniannya. Bentuk kompensasi dari keterlibatan masyarakat melakukan kegiatan restorasi yaitu dengan diperbolehkannya menanam tanaman pertanian. Hal ini disebabkan karena (a) kawasan tersebut merupakan bekas kawasan yang dikelola oleh Perum Perhutani yang telah digarap masyarakat, sekarang masuk wilayah perluasan kawasan TNGHS, (b) Masyarakat sudah terlanjur masuk kawasan untuk menanam tanaman pertanian dan tidak bisa langsung mengusir mereka, (c) Tidak ada upah penanaman, dengan tumpangsari masyarakat mendapat hasil dari tanaman pertanian, dan (d) Tidak ada biaya pemeliharaan.

Sistem tumpangsari (agroforestry) merupakan sistem penanaman campuran antara pohon (tanaman pokok) dan tanaman pertanian. Pemeliharaan tanaman pertanian diharapkan sekaligus juga merupakan pemeliharaan tanaman pokok. Karena kawasan garapan ini sekarang masuk kawasan taman nasional hasil dari perluasan taman nasional, maka kegiatan tumpangsari hanya bersifat sementara, oleh karena itu dalam prakteknya ada beberapa hal penting yang berkaitan dengan kegiatan ini, yaitu:

a. Tumpangsari dituangkan dalam kesepakatan antara petani dan pihak TNGHS dalam bentuk nota kesepahaman (MOU).

b. Waktu untuk tumpangsari hanya dalam kurun waktu dua tahun, setelah itu petani tidak diperbolehkan menanam tanaman semusim.

c. Adanya kegiatan restorasi dengan tumpangsari mengkonsentrasikan kegiatan masyarakat sehingga tidak masuk ke dalam hutan yang masih baik dan lebih mudah dalam pengaturan dan pengawasan.

Untuk jangka pendek diharapkan masyarakat memperoleh penghasilan atau untuk mencukupi kebutuhan pangan mereka dari tanaman sela berupa padi dan sayuran. Untuk jangka menengah dan jangka panjang diperoleh dari hasil buahbuahan dan tanaman obat-obatan, seperti halnya yang dilakukan oleh Balai TN Meru Betiri bekerjasama dengan LSM Latin. Potensi tanaman obat di TN Meru Betiri dijadikan sebagai embrio dalam rehabilitasi kawasan hutan yang melibatkan masyarakat. Masyarakat memperoleh penghasilan dari taman nasional melalui pemanfaatan tanaman obat sebagai bahan baku industri jamu tradisional. Menurut MKI (2005), pada zona rehabilitasi dengan luasan 2.500 ha yang dikelola dengan sistem tumpangsari (wanafarma) bernilai ekonomi Rp 1.976.240.000,-. Kawasan hutan yang direhabilitasi dengan jenis-jenis kemiri (Aleurites molucana), petai (Parkia speciosa), melinjo (Gnetum gnemon) diselingi empon-empon sebagai tumbuhan obat, oleh pihak taman nasional telah dijadikan zona tradisional, di mana pada zona tersebut masyarakat boleh mengambil hasilnya berupa buah dan bibit, tetapi tidak untuk menebang. Contoh bentuk pola tanam pada kegiatan restorasi yang dilakukan oleh masyarakat antara pohon dan tanaman semusim ditampilkan pada Gambar 4.

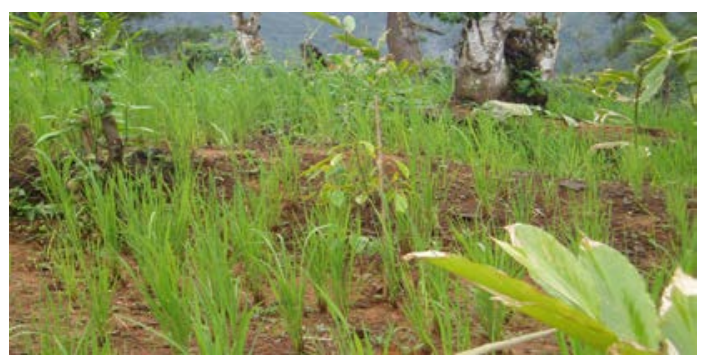

Gambar (Figure) 4. Pola tanam antara pohon, padi, dan kapolaga dalam kegiatan restorasi di Kampung Ci-mapag, Desa Sirnaresmi (Mix plantation model within trees, rice, and capolaga in restoration activities at Kampong Cimapag, Sirnaresmi Village) 
Restorasi yang sedang dilaksanakan TNGHS, juga mengembangan sistem wanafarma. Wanafarma merupakan pola penanaman dengan menggunakan tanaman kayu-kayuan dan tanaman obat-obatan. Tanaman kayu-kayuan yang digunanakan adalah jenis asli taman nasional seperti puspa (Schima wallichii), rasamala (Altingia excelsa), dan huru (Litsea javanica), sedangkan jenis tanaman obat-obatan yang digunakan adalah kapolaga (Amomum cardamomum). Kombinasi kedua jenis tanaman ini dianggap cocok. Tanaman kapolaga merupakan jenis yang tahan terhadap naungan serta tanaman yang tidak memerlukan perawatan secara intensif sehingga nantinya tidak ada lagi pengelolaan lahan secara intensif di kawasan taman nasional. Dalam kegiatan ini pihak taman nasional memberikan bantuan bibit tanaman, pelatihan pertanian kapulaga serta berupaya mencarikan pasarnya, meskipun masyarakat lebih banyak mencari bibit dari lahan sendiri karena memang sejak lama masyarakat telah menanamnya. Diharapkan jenis tanaman obat yang dikembangkan diarahkan pada penggunaan jenis-jenis asli yang telah banyak diketahui.

\section{Melaksanakan Observasi Kawasan}

TNGHS bersama-sama dengan masyarakat lokal melakukan observasi lapangan secara rutin dengan tujuan untuk memantau (monitoring) situasi sekaligus untuk mengurangi kegiatan-kegiatan illegal, serta menjalin hubungan dan kerjasama yang baik antara TNGHS dengan masyarakat lokal melalui komunikasi yang intens. Kegiatan ini dilakukan dengan cara mendirikan tempat kegiatan bersama antara petugas TNGHS dan masyarakat. Bahkan dari pihak taman nasional menugaskan satu orang sebagai pendamping tetap masyarakat dengan harapan lebih banyak sosialisasi dengan masyarakat. Hanya saja berdasarkan pengamatan di lapangan petugas yang ditunjuk oleh TNGHS masih kurang intensif berkomunikasi dengan masyarakat dikarenakan adanya kesibukan lain (Kepala Resort). Oleh karena itu diharapkan untuk ke depannya petugas yang diserahi tugas sebagai pendamping masyarakat tidak diberi beban tugas lain yang tidak berhubungan dengan kegiatan MKK.

\section{Zonasi Sebagai Upaya Pemenuhan Kegiatan Ekonomi Masyarakat}

Zonasi TNGHS sampai saat ini belum dikukuhkan. Oleh karena itu untuk lebih terencana dan terprogram dalam pengelolaannya maka perlu segera dilakukan zonasi taman nasional. Untuk kasus seperti di Kampung Cimapag yang letaknya di luar kawasan taman nasional sedangkan lahan pertanian mereka di dalam kawasan taman nasional, maka dapat diusulkan sebagai zona pemanfaatan tradisional dan zona penyangga atau dengan istilah zona khusus MKK. Dari hasil kajian yang dilakukan oleh Sawitri et al. (2003) disarankan beberapa hal di antaranya adalah zona inti dan zona rimba yang diintervensi oleh masyarakat desa hutan perlu dievaluasi status zonasinya menjadi zona pemanfaatan tradisional. Juga perubahan peruntukan hutan tanaman pinus (seperti di Blok Pondok Injuk) menjadi zona rehabilitasi dengan jenis tumbuhan lokal yang bermanfaat bagi masyarakat. Zona pemanfaatan tradisional untuk memberikan manfaat kawasan secara terbatas dan secara tradisional kepada masyarakat lokal. Fungsi dan sistem pengelolaan yang terstruktur dengan sistem zonasi akan menyelaraskan fungsi pelestarian dan pemanfaatan serta kepentingan sosial ekonomi masyarakat lokal, terutama masyarakat yang masih bergantung pada sumberdaya hutan. Di samping itu, untuk melindungi kawasan TNGHS tersebut dari pemanfaatan illegal, perlu penetapan dan pengelolaan lahan di luar kawasan TNGHS secara intensif untuk kepentingan masyarakat dengan pembangunan dan pengelolaan daerah penyangga.

Kegiatan rehabilitasi yang dilakukan masyarakat hendaknya didukung oleh inovasi teknologi sederhana dan tepat 
guna terhadap masyarakat tertentu dalam upaya pemanfaatan sumberdaya alam hayati non kayu demi kesejahteraan masyarakat dan kelestarian sumberdaya alam hayati tersebut (Kahono et al., 2003). Hasil penelitian yang dilakukan oleh Kalima dan Sutisna (1998) terhadap keanekaragaman rotan menunjukkan bahwa kawasan TNGHS memiliki keanekaragaman rotan cukup tinggi yaitu 13 jenis rotan, maka disarankan menjadikan rotan sebagai pendekatan model pengelolaan serta sebagai sumber nutfah rotan. Kegiatan rehabilitasi dapat menerapkan perpaduan antara tanaman pohon berkayu dan tanaman rotan untuk menggantikan tanaman semusim, sebagai model pemanfaatan kawasan dari hasil hutan non kayu.

Pengelolaan daerah penyangga taman nasional untuk tujuan di atas dilakukan melalui koordinasi dan sinkronisasi dari instansi pelaksana, sehingga pembangunan didukung dan dilakukan oleh berbagai sektor terkait yang saling mendukung. Fungsi kawasan daerah penyangga adalah untuk mendukung peningkatan sosial ekonomi masyarakat, pengembangan wilayah, dan wisata alam. Pengelolaan kawasan budidaya meliputi pengembangan program pertanian terpadu, termasuk menghindari pembakaran, pemakaian herbisida yang berdampak negatif serta menetapkan, baik lokasi pertanian maupun kawasan agroforestry masyarakat yang dapat disertifikatkan sehingga terdapat kepastian berusaha bagi masyarakat lokal dalam pengembangan jenis tumbuhan langka, dan tumbuhan hutan serbaguna yang biasa disebut Multi Purpose Tree Species (MPTS) dalam sistem hutan kemasyarakatan atau hutan rakyat (Bismark, 2002).

\section{KESIMPULAN DAN SARAN}

\section{A. Kesimpulan}

1. Kerusakan Taman Nasional Gunung Halimun Salak di kawasan Pondok Injuk diakibatkan oleh aktivitas penebangan liar dan penggunaan lahan/ perambahan untuk lahan pertanian masyarakat setempat. Kawasan ini sedang mengalami tekanan penduduk akibat dari desakan kebutuhan akan lahan dan hasil hutan.

2. Pembentukan Masyarakat Kampung Konservasi (MKK) Cimapag pada tahun 2004 ditujukan untuk mencegah perladangan dan penebangan liar pada kawasan TNGHS.

3. Kegiatan Restorasi dilakukan oleh enam kelompok masyarakat meliputi kegiatan pengadaan bibit tanaman, penanaman, dan pemeliharaan. Sampai saat ini luas kawasan hutan yang ditanam adalah 49,5 ha dengan jumlah tanaman sebanyak 19.817 pohon yang terdiri dari jenis rasamala (Altingia excelsa Noronha), puspa (Schima wallichii Reinw), dan huru (Litsea javanica BL).

4. Model restorasi yang diterapkan di Kampung Cimapag belum sepenuhnya memenuhi kebutuhan masyarakat setempat akan kayu, hasil hutan lainnya, produk pertanian, kayu bakar, dan pakan ternak, akan tetapi dapat mengurangi aktivitas perladangan dan penebangan liar di kawasan TNGHS.

\section{B. Saran}

Untuk meningkatkan keberhasilan restorasi hutan maka diperlukan koordinasi dan sinkronisasi instansi pelaksana antara Balai Taman Nasional Gunung Halimun Salak dengan Pemerintah Daerah Sukabumi terutama untuk menciptakan kegiatan ekonomi alternatif dan mengurangi ketergantungan masyarakat terhadap kawasan hutan.

\section{DAFTAR PUSTAKA}

Balai Taman Nasional Gunung Halimun Salak dan JICA. 2004. Laporan Hasil Survey Tanah dan Sosial Ekonomi Pertanian. Bogor. Tidak Dipublikasikan.

Bismark, M. 2002. Integrasi Kepentingan Konservasi dan Kebutuhan Sumber 
Penghasilan Masyarakat dalam Pengelolaan Kawasan Konservasi. Prosiding Diskusi Hasil-Hasil Litbang "Rehabilitasi dan Konservasi Sumberdaya Lahan”. Pusat Penelitian dan Pengembangan Hutan dan Konservasi Alam. Bogor.

Departemen Kehutanan. 2007. Taman Nasional Gunung Halimun Salak. www.dephut.go.id/ Informasi/Phpa/ Rappam. htm. Diakses tanggal 10 Mei 2007.

Kahono, S., T. Okamaya, A. J. Arief dan K. Mori. 2003. Hasil-Hasil Penelitian Konservasi Keanekaragaman Hayati. The Biodiversity Conservation Project (BCP). Makalah Seminar dan Lokakarya Pengembangan Model Pengelolaan Taman Nasional Gunung Halimun. Biodiversity Conservation. Bogor.

Kalima, T. dan U. Sutisna. Keanekaragaman dan Keberadaan Jenis Rotan di Gunung Pameungpeuk
Taman Nasional Gunung Halimun, Jawa Barat. Buletin Penelitian Hutan 616 : 27-38. Pusat Penelitian dan Pengembangan Hutan dan Konservasi Alam. Bogor.

MKI. 2005. Potensi Tanaman Obat Mampu Meningkatkan Kesejahteraan Masyarakat di Sekitar Kawasan Hutan. Edisi V.

Sawitri, R., M. Bismark dan N.M. Heriyanto. 2003. Kajian Zonasi Taman Nasional Sebagai Sistem Perlindungan Kawasan dan Pengembangan Agro dan Ekowisata. Buletin Penelitian Hutan 639 : 45-62. Pusat Penelitian dan Pengembangan $\mathrm{Hu}-$ tan dan Konservasi Alam. Bogor.

Setio, P. dan A. S. Mukhtar. 2005. Review Hasil-Hasil Litbang : Pengelolaan Taman Nasional di Indonesia. Pusat Penelitian dan Pengembangan Hutan dan Konservasi Alam. Bogor. 